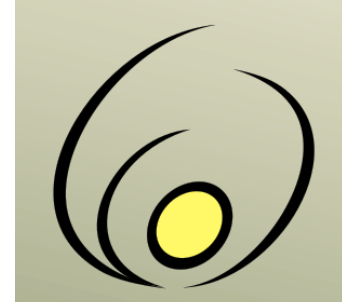

Fórum de Pró-Reitores de Extensão das Instituições Públicas de

Educação Superior Brasileiras

\title{
O papel da divulgação científica em Astrofísica na velhice: relato de uma experiência na extensão universitária
}

\author{
Alan Alves-Brito ${ }^{1}$, Neusa Teresinha Massoni²
}

Resumo: A divulgação das ciências exatas para grupos sociais historicamente marginalizados é um dos grandes desafios da extensão universitária neste século. 0 principal objetivo deste artigo é apresentar os resultados de um projeto de extensão focado na divulgação cultural e científica da Astrofísica para pessoas idosas. Obtivemos, a partir da organização e execução de cursos de difusão científica de Astronomia e Astrofísica, em diferentes contextos, uma excelente aceitação de parte do público idoso, mas identificamos como maior dificuldade o convencimento dos pares na academia de que há interesse e potencial de compreensão de temas científicos nessa faixa etária. Defendemos que esse preconceito aos idosos precisa ser trabalhado e superado. Usando diferentes referenciais teóricos, apresentamos reflexões críticas, bem como discutimos a importância e o impacto de nossas atividades para potencializar e fortalecer a autoestima de pessoas idosas.

Palavras-chave: Educação em Ciências; Cultura científica; Idosos

The role of science communication in Astrophysics in old age: report of an experience in university extension

Abstract: The dissemination of the exact sciences to historically marginalized social groups is one of the greatest challenges of university outreach in this century. The main goal of this paper is to present the results of an outreach project focused on the cultural and scientific dissemination of Astrophysics for elderly people. We obtained from the organization and execution of courses of scientific dissemination of Astronomy and Astrophysics, in different contexts, an excellent acceptance by part of the elderly public, but we identified as a greater difficulty the convincing of peers in the academy that there are interest and potential for understanding scientific topics in this age group. We argue that these misconceptions against the elderly need to be worked on and overcome. Using different theoretical references, we present critical reflections, as well as discuss the importance and impact of our activities to enhance and strengthen the self-esteem of elderly people.

Keywords: Science Education; Scientific culture; Elderly
Originais recebidos em

01 de abril de 2020

Aceito para publicação em

06 de julho de 2020

1 Universidade Federal do Rio Grande do Sul (UFRGS)

alan.brito@ufrgs.br

(autor para correspondência)

2 Instituto de Física, Universidade Federal do Rio Grande do Sul (UFRGS) 


\section{Introdução}

A divulgação científica, principalmente de áreas historicamente construídas e dominadas por certos grupos identitários (homens, brancos, heterossexuais e bem nascidos), como é o caso da Física e da Astrofísica, é uma das formas mais eficazes de problematizar e expandir as teias de conhecimento na sociedade brasileira e propiciar a inclusão que se almeja no século XXI, isto é, oferecer oportunidades a que todos os cidadãos possam conhecer e acompanhar a ciência e tecnologia e seus avanços.

No caso do Brasil, em que grande parcela de sua população está à margem dos processos de produção do conhecimento científico e tecnológico, a divulgação científica é um dos segmentos da extensão universitária mais cruciais, para não apenas estreitar a relação universidade-sociedade, mas também pensar formas diferenciadas de saber, conhecer e se comunicar com diferentes grupos sociais (Valadares, 2001; Fórum dos Pró-Reitores de Extensão das Universidades Públicas Brasileiras, 2007).

A Astronomia é uma das ciências básicas mais instigantes. Interdisciplinar por natureza, ela consegue atrair a atenção de crianças, adolescentes, jovens, adultos e idosos. Apesar disso, estaria essa ciência acessível a todos os segmentos da população brasileira? Segundo dados da Organização Mundial de Saúde (2005), a população brasileira com 60 anos ou mais duplicou em duas décadas (1980-2000), mas o aumento da expectativa média de vida não é acompanhado pela melhoria ou manutenção da qualidade de vida, tanto com relação à saúde e segurança, quanto ao lazer e cultura.

Assim, a preocupação com o envelhecimento saudável para todos(as) os(as) idosos(as) precisa mobilizar, não apenas as políticas públicas, mas a sociedade e suas instituições - como as universidades, por exemplo - para que o idoso seja um recurso cada vez mais valioso para suas famílias, comunidades e para o País.

Neste sentido, pensar a divulgação científica da Astrofísica na velhice é tão desafiador quanto necessário. Por um lado, do ponto de vista da divulgação científica, em si, no Brasil e na América Latina, os resultados são preocupantes. De acordo com o recente documento "Diagnóstico da Divulgação da Ciência na América Latina" (Patiño Barba et al., 2017), de um total de 123 organizações identificadas em 14 países da região, 70,7\% das instituições que fazem divulgação da ciência na América Latina são públicas, enquanto $29,3 \%$ são privadas. Esse mesmo estudo revela que apenas $8,1 \%$ dos profissionais que atuam com divulgação de ciência e tecnologia na América Latina são remunerados pelo trabalho; 60,2\% são voluntários, enquanto 31,7\% são voluntários e remunerados.

Em número de instituições que fazem divulgação científica e tecnológica na América Latina, o Brasil ocupa a segunda posição (25\%); o México vem em primeiro lugar (33,6\%) e, depois do Brasil, aparece a Argentina (19\%). As instituições de nível superior, em que se insere o presente estudo, representam apenas $27,6 \%$ dentre as que executam ações de divulgação científica e tecnológica nos países estudados. Ainda mais relevante para este estudo, o público alvo principal a que se destinam as atividades de divulgação são adolescentes entre 13 e 18 anos (42,9\%), crianças menores de 12 anos (28,9\%) e adultos (29,2\%). Como se vê, os idosos não são alcançados por atividades de divulgação científica.

Por outro lado, embora o Brasil tenha a vantagem de ter reconhecida experiência acumulada em quase dois séculos de história no que tange à circulação dos resultados de ciência e tecnologia (Moreira \& Massarani, 2001), e detenha prestígio internacional por seu potencial econômico, industrial e estratégico nas Américas e no globo, o país ainda possui uma plataforma limitada e elitizada de divulgação tecnológica e científica em todas as regiões da federação, sobretudo nas regiões mais vulneráveis socialmente, como as regiões Norte e Nordeste. 
Em linhas gerais, não é exagero afirmar que faltam ainda ao nosso país políticas públicas claras, consistentes, eficazes, e com estratégias e planejamentos bem delineados. No caso particular de ações, programas e projetos de divulgação científica em Astronomia e Astrofísica, constata-se que a grande maioria dos editais elaborados por agências públicas federais ou estaduais, e também por instituições privadas, com o objetivo de fomentar a divulgação e a popularização da ciência, não contempla, na maioria das vezes, crianças e idosos.

Diferentes razões poderiam explicar este fenômeno: (i) a sociedade e os modelos de educação e avaliação vigentes, essencialmente capitalistas, preocupados em checar a aprendizagem de conteúdos específicos e devotados ao treinamento para alcançar um alto desempenho em exames de larga escala - modelos que foram mercantilizados e perderam o sentido clássico de ofício, ou seja, o de alcançar o conhecimento pelo gosto, aquele que busca entender a relação com o que se faz como uma maneira de entender a vida e a responsabilidade com o mundo (Larrosa, 2018); essa separação tem permitido mais facilmente negar e excluir a infância e a velhice de seus processos de construção intelectual; (ii) nesse tipo de sociedade, crianças e idosos são considerados despreparados e incapazes intelectualmente de observar a Natureza, aprender a ciência, e de processar imagens e informações cognitivas que envolvam o conhecimento técnico-científico ou formular raciocínios mais abstratos (lógico-matemáticos, por exemplo); (iii) nas representações sociais, crianças e idosos são vistos como incapazes de criar diferentes modelos mentais para auxiliá-los a ler o mundo à sua volta e de se interessar pelo conhecimento científico, simplesmente por que supostamente estariam distanciados "das retóricas habituais sobre a profissão e o profissionalismo, sobre a eficácia e a rentabilidade" (ibid., p. 27), isto é, estão fora do mercado de trabalho. Interessantemente, crianças e idosos representam as duas camadas que não contribuem, com trabalho, para a sociedade capitalista de consumo (Bauman, 1998).

Vale ainda salientar que discutir questões tecnológicas e científicas, bem como fomentar a cultura científica na velhice torna-se cada vez mais relevante dado que, do ponto de vista estatístico, a Organização das Nações Unidas (ONU) considera o período que vai de 1975 a 2025 como a Era do Envelhecimento.

Apenas para especificar um pouco mais, vale destacar que no Brasil, segundo dados do Instituto Brasileiro de Geografia e Estatística (IBGE), cerca de 4,95\% da população brasileira era de idosos (acima de 60 anos) nos anos 1970, enquanto na década de 1990 o percentual saltou para 8,47\% e este percentual tende a aumentar como foi comentado.

Além disso, o Estatuto do Idoso no Brasil, em seu Art. $3^{\circ}$ do Título I, resguarda que "É obrigação da família, da comunidade, da sociedade e do Poder Público assegurar ao idoso, com absoluta prioridade, a efetivação do direito à vida, à saúde, à alimentação, à educação, à cultura, ao esporte, ao lazer, ao trabalho, à cidadania, à liberdade, à dignidade, ao respeito e à convivência familiar e comunitária". Fica claro, então, que não se pode excluir a velhice dos produtos gerados pelo desenvolvimento científico e tecnológico do século XXI em qualquer nação democrática que respeite os direitos de todas as pessoas.

Com esta preocupação, o presente artigo traz um relato de experiência, apresentando detalhadamente um curso realizado com idosos do Programa Universidade da Terceira Idade (UNITI) da Universidade Federal do Rio Grande do Sul. O presente artigo vislumbrou, no contexto global, (i) trazer à discussão o papel da divulgação da Astrofísica na velhice; (ii) relatar a assimilação conceitual e abstrata por parte desse grupo durante a realização do curso de difusão cultural; (iii) analisar a postura e o interesse do grupo em questões relacionadas à ciência e à tecnologia; e (iv) comparar a percepção da Astrofísica por parte do grupo idoso com outros grupos (adolescentes e adultos não idosos) oriundos de outras experiências vivenciadas, não apenas pelos autores do presente artigo, mas também com base em dados da literatura. 


\section{Procedimentos metodológicos}

Do ponto de vista metodológico este artigo é uma narrativa de experiência didática de divulgação científica vinculada a um projeto de extensão universitária. O caráter crítico e reflexivo da narrativa justifica a busca constante em estabelecer um diálogo com a literatura e com pensadores contemporâneos. Ao mesmo tempo, objetiva-se fazer uma análise interpretativa preliminar de alguns resultados obtidos com a aplicação das atividades de divulgação científica com idosos comparando-os aos de outras aplicações, com outros públicos.

\section{Referenciais teóricos}

As ações de educação e de difusão cultural e científica da presente proposta estiveram norteadas pela noção de transposição didática e de aprendizagem significativa. O conceito de transposição didática (Chevallard \& Johsua, 1982) leva em conta as transformações sofridas por um conceito desde sua produção no "saber sábio" até o momento de sua introdução nas salas de aula ("saber ensinado"), isto é, ocorrem modificações de natureza epistêmica no caminho que vai da pesquisa ao ensino. Ter em mente que não se ensina saberes "em estado puro" e que ocorre um complexo cruzamento entre uma lógica conceitual e os projetos de formação, neste caso de divulgação, e as necessidades didáticas é fundamental para o desenvolvimento de conexões de aprendizagem relacionando a Astronomia e a Astrofísica com as demais áreas do conhecimento.

Portanto, a metodologia de trabalho adotada privilegiou o diálogo, a participação ativa nos questionamentos e nas atividades práticas, levando em conta o que se mapeou (isto é, os conhecimentos prévios dos sujeitos que aprendem, ou subsunçores, nas palavras de David Ausubel, precisam ser minimamente conhecidos para que se possa iniciar a prática didática, ancorando neles os novos conhecimentos) no diálogo inicial de cada encontro, e buscando favorecer a compreensão dos indivíduos envolvidos no processo de divulgação, em detrimento à memorização de conteúdos e informações. Na acepção da psicologia cognitiva de David Ausubel, buscamos favorecer a aprendizagem significativa em detrimento a um tipo de aprendizagem considerada mecânica.

Durante e após cada apresentação, o público de terceira idade era incentivado a expor perguntas e a sanar dúvidas, por mais simples que estas lhes pudessem parecer. Os assuntos trabalhados nas ações foram escolhidos a partir dos documentos oficiais de Educação Básica, favorecendo não apenas a articulação de competências e habilidades, mas priorizando uma linguagem acessível e promovendo cruzamentos de saberes interdisciplinares (Secretaria de Educação Fundamental 1998; Conselho Nacional de Educação 2011; Ministério da Educação, $\mathrm{S} / \mathrm{d}^{1}$ ).

As atividades foram também tratadas em sinergia às ideias da escritora e pensadora francesa, Simone de Beauvoir (1908-1986), umas das mais famosas e influentes intelectuais do feminismo moderno, que também analisou a condição da "velhice" na sociedade (Beauvoir, 1990). Segundo seus estudos, a velhice é apenas mais um processo de vida do ser humano, durante a qual o velho apresenta desejos e as mesmas inquietações que os jovens. Para Beauvoir, tanto a imagem de virtude quanto a imagem de degradação ratificam e posicionam a velhice fora do contexto da humanidade. Dessa forma, assim como a infância, a velhice precisa ser vista como uma fase que contempla sujeitos ativos, que têm vontades, direitos, e que carregam consigo uma infinidade de saberes, experiências. Além disso, as ideias aqui apresentadas baseiam-se no conceito de geração, conforme discutido em Bourdieu (1983) e Mannheim (1993).

Amparados pelo referencial da teoria da aprendizagem significativa de David Ausubel (Ausubel et al., 1980), tivemos como preocupação central alcançar uma aprendizagem com significado. Isto é possível, segundos esses autores, se a nova informação se relacionada com conhecimentos relevantes, preexistentes na estrutura cognitiva dos sujeitos que aprendem, aos que Ausubel denomina de subsunçores. Desta forma, só seria 
possível conduzir o curso com alguma possibilidade de sucesso se, minimamente, pudéssemos mapear os conhecimentos prévios dos participantes, isto é, aqueles resultantes de suas trajetórias de vida, de trabalho, de educação formal e experiencial. Com tal mapeamento pudemos levar em conta o que sabiam e, assim, fazer uma escolha adequada do tipo de linguagem empregada nas apresentações e discussões de conceitos e modelos de Astrofísica e Astronomia.

Por essa razão, cada início de encontro com os idosos foi marcado por momentos de diálogo, que se estenderam por muitos minutos; nesses momentos eles eram incitados a conversar, contar o que sabiam, ou pensavam saber sobre os temas que seriam tratados. Na sequência, os temas eram introduzidos, apresentados utilizando-se diferentes recursos, e sempre finalizando com novas discussões (Quadro 1).

\section{Coleta de dados e diagnóstico do público alvo}

As reflexões aqui apresentadas baseiam-se em coleta de dados por meio de questionários e/ou relatos e de uma análise estatística descritiva acompanhada de interpretação de respostas a perguntas abertas. Primeiramente, analisamos as respostas dadas pelos participantes a um "questionário de perfil" que teve o objetivo de caracterizar o grupo. Analisamos interpretativamente a pertinência de perguntas feitas pelos participantes ao longo do curso, bem como suas respostas ao questionário final de avaliação, que contou com perguntas básicas (relatos abertos) sobre a experiência de cada um.

O curso contou com a participação de 140 mulheres e cinco homens, com idades entre 65 e 91 anos, integrantes do Programa UNITI da UFRGS. O grupo se distribuía em variados níveis de escolaridade, do Ensino Fundamental ao Superior. A maioria possuía nível superior e, em alguns casos, pós-graduação. A maioria dos participantes se autodeclarou "aposentado", tendo exercido diferentes funções ao longo da vida. O cargo de "professor" foi a função identificada como predominante no grupo. Além disso, os participantes declararam que vivem, em sua maioria, sozinhos e ganham entre 6-10 salários (Figuras 1 e 2). Finalmente, de acordo com a Figura 3, a atividade recreativa e de lazer preferida da maioria dos participantes foi a leitura.

\section{Estrutura do curso}

O curso de difusão científica (Figura 4) foi realizado entre maio a novembro de 2015 no auditório da Faculdade de Biblioteconomia e Comunicação da UFRGS, contando com a participação de profissionais (professores, pósdoutorandos e bolsistas de iniciação científica) do Departamento de Astronomia do Instituto de Física da UFRGS (Quadro 1).

Foram realizados, no total, seis encontros, com duas horas e meia de duração cada, que contaram com a presença média de 135 pessoas. Usando a Astronomia e a Astrofísica como elementos motivadores, o projeto surgiu da necessidade de expandir os horizontes culturais e científicos na velhice em relação a perguntas científicas e filosóficas da ciência contemporânea e da Astronomia e Astrofísica. Em particular exploraram-se questões como: de que é constituído o Universo? O que é a vida? De onde viemos? Para onde vamos?

A exemplo do princípio que consta dos projetos ${ }^{2}$, alinhamo-nos ao novo conceito de "desaposentadoria" no sentido de que pessoas idosas, aquelas que concluíram seu percurso laboral, podem, e devem, continuar ativos, envolvidos em atividades prazerosas, compartilhando saberes, discutindo filosofia e poesia, e, porque não, Ciência, Astronomia e Astrofísica? O que é a vida? De onde viemos? Para onde vamos? 
Quadro 1: Atividades realizadas no curso Astronomia e Astrofísica: Ciência e Cultura na Terceira Idade.

\begin{tabular}{|c|c|c|}
\hline Tópico & Objetivos & Metodologia \\
\hline $\begin{array}{l}\text { Luz, câmera, ação: a } \\
\text { interação luz- } \\
\text { matéria e as escalas } \\
\text { de distância e } \\
\text { tamanho no } \\
\text { Universo }\end{array}$ & $\begin{array}{l}\text { - compreender como a luz e a matéria interagem no } \\
\text { Universo, } \\
\text { - visualizar as escalas de distância e tamanho, do } \\
\text { micro ao macro, } \\
\text { - oferecer uma visão geral da Astrofísica, cobrindo } \\
\text { aspectos históricos e filosóficos da ciência. }\end{array}$ & $\begin{array}{l}\text { - exposição } \\
\text { - projeções de lâminas, } \\
\text { - simulações, } \\
\text { - vídeos, } \\
\text { - discussões. }\end{array}$ \\
\hline Telescópios & $\begin{array}{l}\text { - estudar o princípio de funcionamento dos telescópios, } \\
\text { - entender como são feitas as imagens (fotometria e } \\
\text { espectroscopia) dos variados objetos astronômicos. }\end{array}$ & $\begin{array}{l}\text { - Exposição } \\
\text { - projeções, } \\
\text { - simulações, } \\
\text { - vídeos, } \\
\text { - interação com um } \\
\text { telescópio de } 90 \mathrm{~cm} \text {, } \\
\text { - discussões. }\end{array}$ \\
\hline $\begin{array}{l}\text { O sistema solar, } \\
\text { exoplanetas e a vida } \\
\text { no Universo }\end{array}$ & $\begin{array}{l}\text { - esquematizar os principais elementos do sistema } \\
\text { solar, } \\
\text { - contrastar os diferentes sistemas planetários, } \\
\text { - discutir qual é a base da vida e sua condição de } \\
\text { existência no Universo. }\end{array}$ & $\begin{array}{l}\text { - exposição } \\
\text { - projeções, } \\
\text { - simulações, } \\
\text { - vídeos, } \\
\text { - discussões. }\end{array}$ \\
\hline $\begin{array}{l}\text { Nascimento, vida e } \\
\text { morte das estrelas }\end{array}$ & $\begin{array}{l}\text { - entender como as diferentes estrelas do Universo se } \\
\text { formam, vivem e morrem, } \\
\text { - compreender como os diferentes elementos químicos } \\
\text { da tabela periódica se formam no Universo. }\end{array}$ & $\begin{array}{l}\text { - exposição } \\
\text { - projeções, } \\
\text { - simulações, } \\
\text { - vídeos, } \\
\text { - discussões. }\end{array}$ \\
\hline $\begin{array}{l}\text { Galáxias e } \\
\text { aglomerados de } \\
\text { galáxias }\end{array}$ & $\begin{array}{l}\text { - compreender que são galáxias e os diferentes } \\
\text { aglomerados de galáxias, } \\
\text { - discutir as maiores estruturas do Universo. }\end{array}$ & $\begin{array}{l}\text { - exposição } \\
\text { - projeções, } \\
\text { - simulações, } \\
\text { - vídeos, } \\
\text { - discussões. }\end{array}$ \\
\hline $\begin{array}{l}\text { Cosmologia: a } \\
\text { origem do Universo }\end{array}$ & $\begin{array}{l}\text { - discutir os principais modelos acerca da origem do } \\
\text { Universo, } \\
\text { - apresentar os conceitos de massa e energia escura, } \\
\text { - visualizar como as galáxias se formam, } \\
\text { - compreender que o Universo é finito no tempo e no } \\
\text { espaço, mas expande de maneira acelerada para o } \\
\text { infinito. } \\
\text { - compreender a ciência como construção humana e } \\
\text { parte da cultura. }\end{array}$ & $\begin{array}{l}\text { - exposição com } \\
\text { projeções, } \\
\text { - simulações, } \\
\text { - vídeos, } \\
\text { - discussões. }\end{array}$ \\
\hline
\end{tabular}




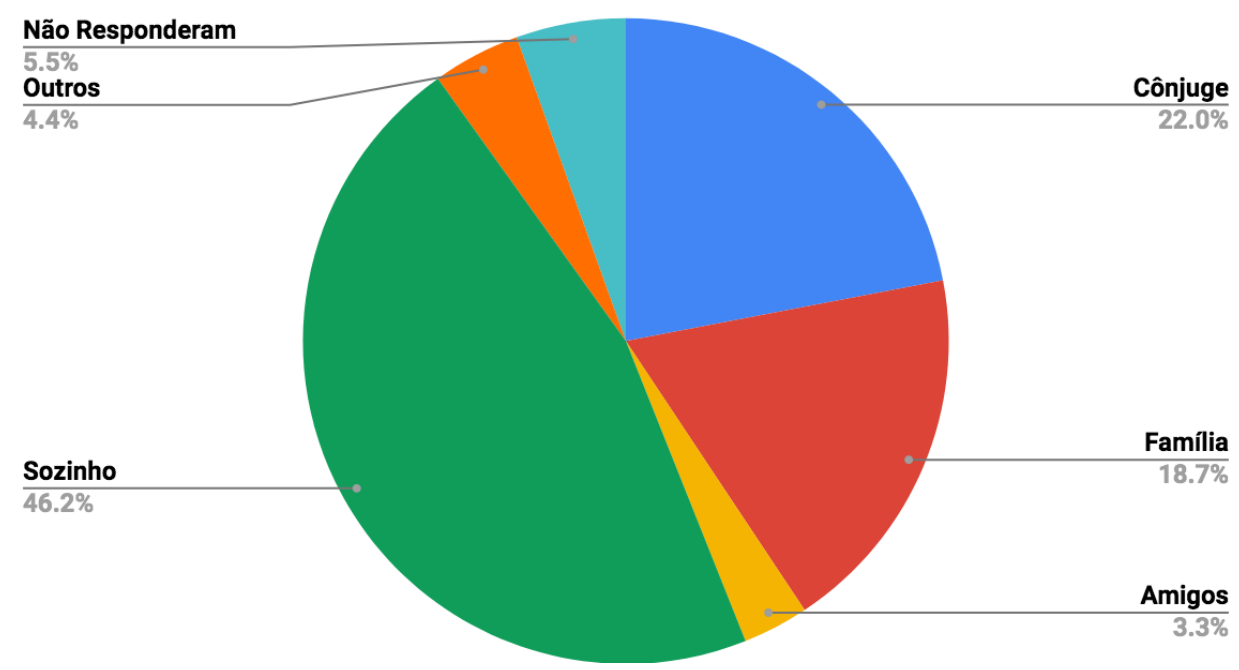

Figura 1. Situação domiciliar (com quem reside) dos participantes.

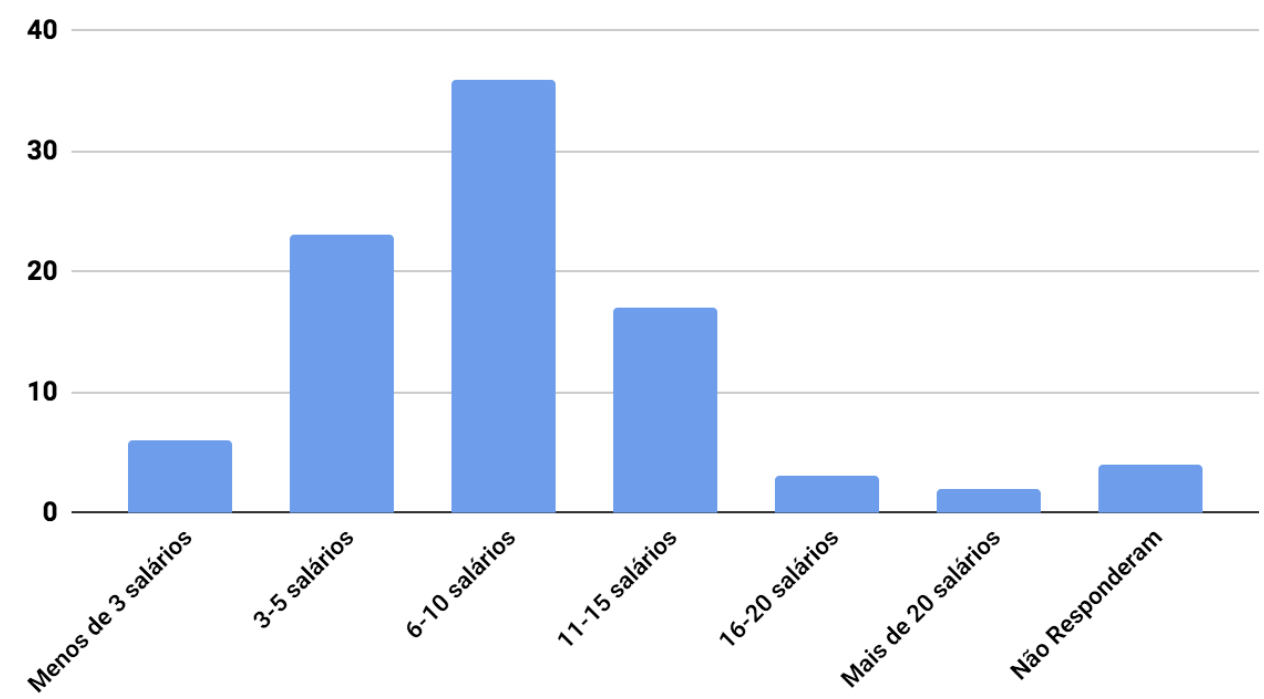

Figura 2. Distribuição de renda dos participantes.

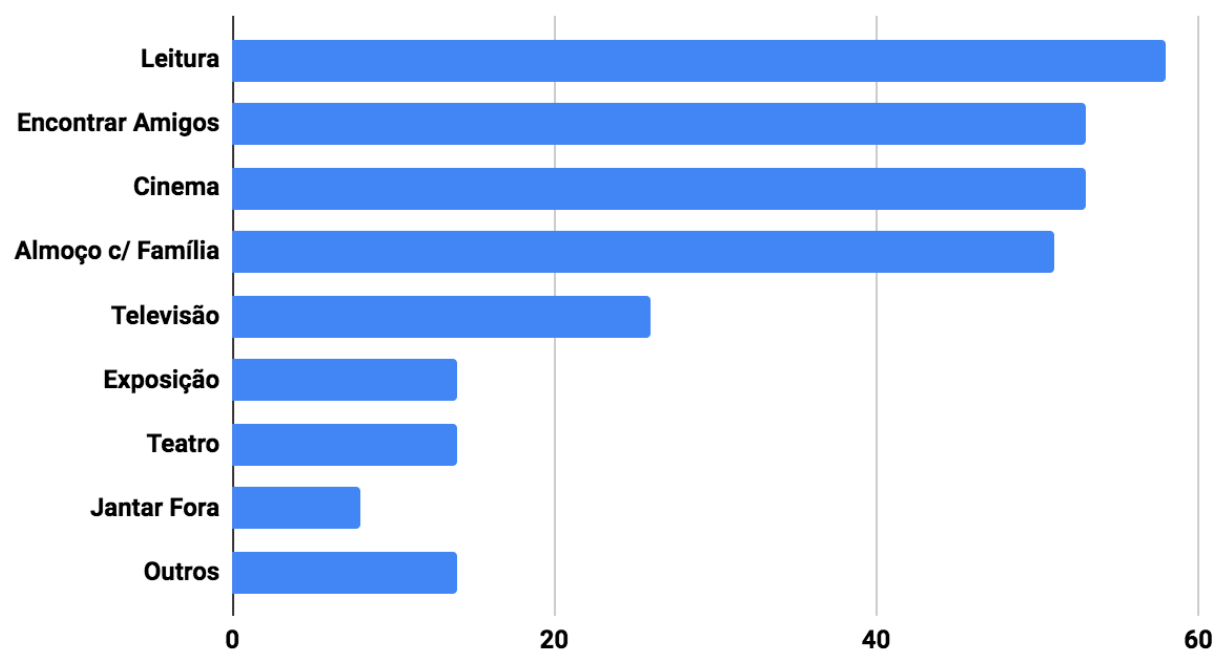

Figura 3. Atividades de lazer mais citadas como preferidas pelos participantes. 


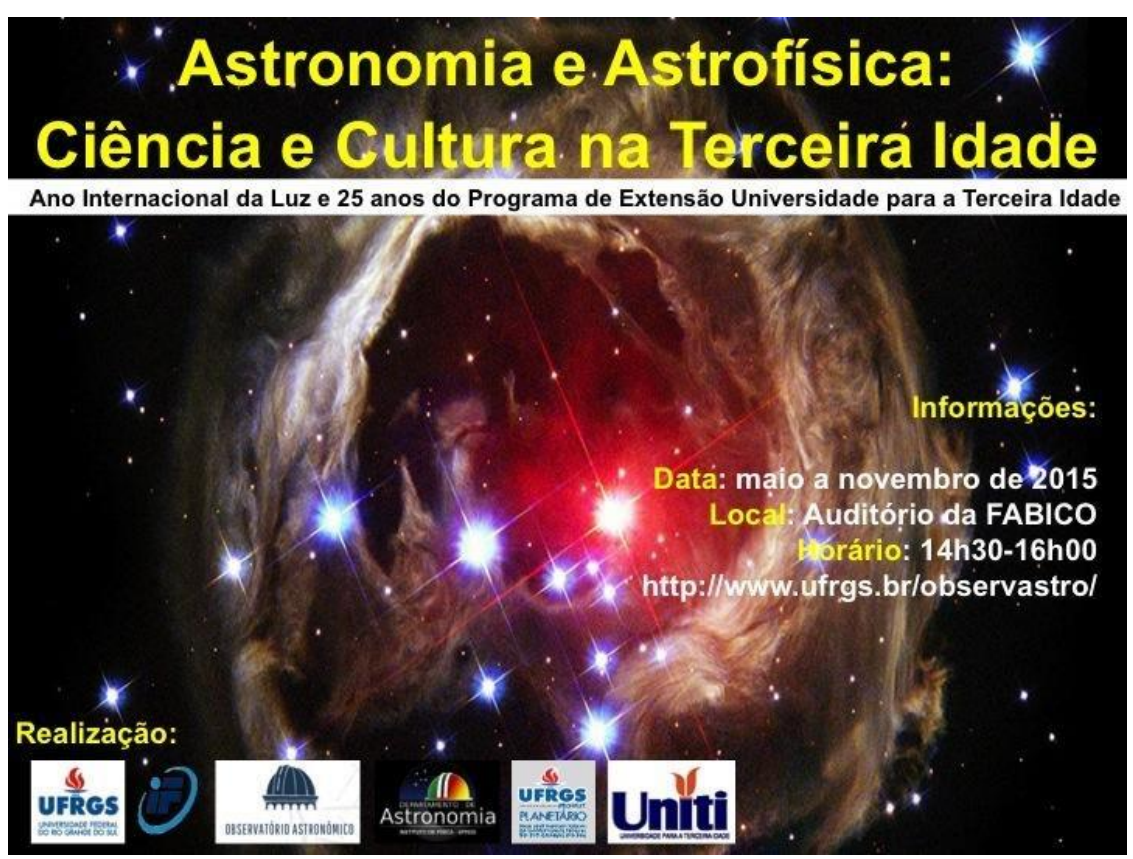

Figura 4: Cartaz de apresentação do curso.

\section{Resultados e Discussão}

Com base no material coletado e nas análises qualitativas de cada encontro, apresentamos na sequência alguns de nossos resultados mais importantes seguidos de reflexões críticas.

Nas três experiências que tivemos com a organização e execução de cursos de difusão científica de Astronomia e Astrofísica orientados ao público idoso, no Chile, em 2010 e em 2011, e no Brasil em 2015, a maior dificuldade enfrentada foi convencer alguns colegas da comunidade acadêmica - professores, pesquisadores e técnicos de que há, na velhice, interesse por temas científicos e tecnológicos e que estas pessoas podem não apenas assimilar conceitos e abstrações físico-matemáticas, como também entender como as sinapses científicas e a leitura e interpretação das leis e dos fenômenos naturais se processam e repercutem na sociedade.

O preconceito contra o público idoso, quando se trata de planejar atividades de divulgação científica em ambientes acadêmicos, é latente. Ainda que haja uma postura similar no trato com o público infantil, no sentido de que também este é subestimado do ponto de vista da divulgação científica, a questão dos idosos passa por um aspecto ainda mais crucial: a velhice parece ser um tabu, como discute Simone de Beauvoir em sua obra (Beauvoir, 1990). Enquanto a infância inspira vida, princípio e futuro, a velhice parece denunciar a finitude humana e, portanto, desestimulante quando se trata de propor atividades de divulgação científica. Grande parte das atividades voltadas para o público idoso centraliza-se na promoção de atividades recreativas e musicais ou se foca em discutir patologias típicas dessa fase da vida.

Para ilustrar que, infelizmente, não se trata de sobremaneira de um exemplo isolado, vale ressaltar que durante a apresentação dos projetos pautados na velhice durante o XIV Salão UFRGS de Extensão, em 2015, o projeto narrado no presente artigo foi o único focado nas potencialidades da velhice; todos os outros projetos avaliados na sessão apresentavam como tema principal patologias e/ou limitações físicas típicas da velhice.

Contudo, as observações indicam que na aplicação de nosso projeto, o público idoso não apenas foi capaz de assimilar conceitos novos (físicos e matemáticos), como foi também capaz de confrontar o "conhecimento 
novo" com o conhecimento que já traziam, fornecendo alguns indícios de que houve alguma aprendizagem significativa e, especialmente, motivação e satisfação frente ao novo. Isso ficou notório através das perguntas típicas formuladas durante e após as apresentações e realização de atividades variadas. As perguntas e manifestações claramente expunham a 'tensão' entre o novo e o velho conhecimento que essas pessoas traziam, como demonstra a frase abaixo, de uma das participantes do curso.

"Professor, eu nunca imaginei que houvesse tanta beleza e tanta coisa fora da Terra. Eu estou impressionada".

O resultado mais importante da experiência com o curso foi perceber que a Astrofísica não é uma ciência "longínqua" da realidade como muitos imaginam, além de poder ser discutida e assimilada entre pessoas idosas. Ficou-nos claro que a Astrofísica pode servir de interface rumo a sinapses complexas, passando por conceitos físicos, matemáticos e filosóficos da ciência e da tecnologia, sem desrespeitar a experiência e o arcabouço social e cultural que os idosos trazem consigo. O público alvo se sentiu completamente à vontade com os temas discutidos fazendo perguntas constantemente.

Percebemos com essa experiência que o papel principal da divulgação da Astrofísica na velhice é, sem dúvida, promover a inclusão científica, mas também expande os horizontes científicos na velhice e contribui com a socialização do conhecimento. Desde atividades de divulgação que abordaram temas básicos da Astronomia de Posição, até ideias mais elaboradas sobre a origem do Universo no contexto cosmológico, acabaram por reconhecer o 'velho' como sujeito social, político e cultural.

Do ponto de vista social, Simone de Beauvoir propõe que a percepção do velho na sociedade não é das mais confortáveis. Essa visão não mudou significativamente desde a publicação de seus clássicos "A Velhice" (Beauvoir, 1990), pois vivemos em uma sociedade onde as relações de poder estão, de certa maneira, pautadas na economia e, como ressalta Beauvoir, "a economia é baseada no lucro; é a este, na prática, a que toda civilização está subordinada: o material humano só interessa enquanto produz" (Beauvoir, 1990). Dessa forma, por estar a velhice "fora do mercado", ela é automaticamente excluída de vários bens culturais, inclusive o científico, o que se acentua principalmente nas camadas mais vulneráveis da sociedade (Debert [2004] faz uma crítica ao capitalismo e ao sistema econômico-social no contexto do discurso gerontológico).

Do ponto de vista político, há poucas iniciativas públicas, no Brasil, focadas na promoção do desenvolvimento científico na velhice. Os editais específicos das três esferas de poder (municipal, estadual e federal) que buscam fomentar a divulgação das ciências básicas entre a população, o que inclui a Astronomia, não contemplam adultos com faixa etária igual ou superior a 60 anos, o que é lamentável, já que, em muitos casos, esse público não teve a oportunidade de acesso ao conhecimento científico especializado em suas formações escolares e/ou universitárias. Uma vez mais, a realização de cursos de divulgação científica focados na velhice ajuda a fortalecer políticas públicas focadas nessa faixa etária.

Do ponto de vista cultural, conforme propõe Chauí (1995), a cultura deve ser um direito dos cidadãos, enquanto a cidadania cultural deve ser adotada como política pública. No entanto, a velhice está frequentemente à margem da cultura científica e, especificamente, dos benefícios que a divulgação da Astrofísica pode promover.

As constelações, por exemplo, sumarizam o olhar de diferentes culturas ao longo da história, e a Astronomia representa uma oportunidade ímpar de revisitar essas culturas.

Vale ainda refletir as ideias de Bourdieu sobre o conceito de geração, no sentido de que esta é tratada a partir de uma perspectiva relacional: jovem está em oposição a adulto ou velho. Em seu texto "A juventude é apenas uma palavra" (Bourdieu, 1983), Bourdieu destaca que "somos sempre o jovem ou o velho de alguém". Outro 
conceito interessante de geração que podemos levar em conta para a interpretação dos nossos resultados é o conceito de juventude do sociólogo húngaro Karl Mannheim (1893-1947). Para ele, geração é a convivência, em um dado momento histórico, de populações que nascem em períodos distintos da história; juventude é uma construção da modernidade. Há, em suas ideias, uma linearização da história. É como se a história fosse uma sucessão de fatos em uma linha de tempo. A história da ciência, por sua vez, é não linear e atemporal. Não faz sentido deixar a velhice à margem de atividades voltadas para a divulgação da ciência e da tecnologia, em qualquer sociedade.

Outro aspecto importante de ressaltar em nossa experiência foi o interesse demonstrado pelos idosos durante os encontros. Não houve, por parte do grupo, qualquer problema de concentração e envolvimento durante as atividades. Escutavam atentos e interrompiam sempre que necessário. Contrariamente ao que se imagina, os idosos eram pontuais e participavam de maneira proativa das atividades propostas. As dúvidas se dividiam entre questões básicas (por exemplo, a diferença entre estrela e planeta; se a "estrela Dalva" é mesmo uma estrela) até questões mais complicadas e ainda não resolvidas da Astrofísica (por exemplo, definição e observação da matéria e energia escura), passando ainda por questões relacionadas ao impacto das tecnologias usadas na área (sondas, satélites, telescópios). Ficou evidente ao longo do curso que o público alvo lia muito e trazia consigo dúvidas variadas, quase sempre descontextualizadas.

No primeiro encontro de nosso curso foi perguntado aos participantes o que estes pensavam do Universo: $O$ que era o Universo para eles? As respostas foram diversas, mas todas na direção de que o Universo se resumiria ao sistema Sol-Terra-Lua. Os que citavam estrelas e galáxias, o faziam "de ouvido" apenas, ou seja, do que ouviram falar desses objetos, mas sem ter certeza de "o que" são feitos e as implicações por trás de seus estudos detalhados. A concepção de que o Universo corresponderia ao sistema Sol-Terra-Lua foi comum entre os mais diversos tipos de experiências de divulgação em Astronomia. Embora muitos soubessem da existência de estrelas e galáxias, foi possível perceber que lhes faltava o conceito e a ideia de como se organiza a "arquitetura do Universo".

O Quadro 2 resume ideias predominantes dos participantes do curso aqui narrado e que, de certa maneira, foi recorrente em cursos de extensão ou de divulgação realizados em outros públicos (adolescentes e adultos).

Uma análise preliminar do Quadro 2 indica que idosos(as), assim como outros grupos (jovens da educação básica, universitários e adultos não idosos), apresentavam pré-concepções muito similares. Crenças como: $O$ sistema solar é formado por Sol-Lua e planetas apenas; o Sol que se move, e não a Terra, estrela cadente é, de fato, uma estrela; a distância Terra-Sol explica as estações do ano (a Terra estar no afélio ou periélio, ou seja, ponto mais afastado e mais próximo, respectivamente, da órbita elíptica da Terra, define as estações), entre outras, em várias áreas da Física e da Ciência em geral (Peduzzi, 2005; Silveira, 2013; Krause \& Scheid, 2018) são conhecidas na literatura como "concepções alternativas" (alternativas porque divergem daquelas aceitas pela comunidade científica). Elas também são comuns entre crianças no início da educação formal, até jovens e adultos em idade universitária (Hoffmann, 2017).

Com os idosos com quem trabalhamos em nosso projeto não foi diferente. Isto nos sugere que o funcionamento das estruturas cognitivas de idosos e aquelas que ocorrem em aprendizes de outras faixas etárias são similares. Embora este resultado necessite de uma análise sistemática mais aprofundada, ele indica que não há razão para não investirmos na divulgação científica na velhice. 
Quadro 2. Preconcepções dos idosos sobre temas variados da Astronomia e Astrofísica.

\begin{tabular}{|c|c|}
\hline Assunto & Ideias predominantes \\
\hline Sistema Solar & $\begin{array}{l}\text { - O próprio Universo. } \\
\text { - Formado pelo Sol, Lua e planetas apenas. }\end{array}$ \\
\hline $\begin{array}{l}\text { Movimento da Terra e movimento } \\
\text { aparente do Sol }\end{array}$ & $\begin{array}{l}\text { - A Terra apresenta dois movimentos: rotação e translação. } \\
\text { - Visão Aristotélica recorrente: o Sol que se move, e não a Terra. }\end{array}$ \\
\hline Vênus: estrela ou planeta & $\begin{array}{l}\text { - A estrela D'alva é uma estrela (poucos sabem que, na verdade, } \\
\text { trata-se do planeta Vênus). }\end{array}$ \\
\hline Estações do ano & $\begin{array}{l}\text { - A distância Terra-Sol explica as estações do ano. } \\
\text { - Poucos sabem de quanto está inclinada a Terra. } \\
\text { - Não conectam a inclinação da Terra com a incidência dos raios } \\
\text { solares. }\end{array}$ \\
\hline $\begin{array}{l}\text { Movimento da Terra e movimento } \\
\text { aparente do Sol }\end{array}$ & $\begin{array}{l}\text { - Há uma confusão para entender que o Sol não se move } \\
\text { diariamente mas sim é a Terra }\end{array}$ \\
\hline Meteoros/Meteoritos/Meteoroides & $\begin{array}{l}\text { - Quase ninguém sabe diferenciar. } \\
\text { - Estrela cadente é, de fato, uma estrela. }\end{array}$ \\
\hline Lua & $\begin{array}{l}\text { - Desconhecem sua formação. } \\
\text { - Não tem rotação e nem translação. } \\
\text { - Não mostra a mesa face. } \\
\text { - } \text { Tem lado escuro. } \\
\text { - Desconhecem os ciclos. } \\
\text { - As fases são consequência de sombra. } \\
\text { A lua apresenta quatro fases, cada uma de sete dias. }\end{array}$ \\
\hline Constelações & $\begin{array}{l}\text { - Conjuntos de estrelas. } \\
\text { - Não há mais nada em uma constelação, somente estrelas. } \\
\text { - As constelações apresentam o mesmo tamanho e são apenas } \\
\text { doze }\end{array}$ \\
\hline Estrelas & - A colisão de estrelas é frequente no Universo. \\
\hline Anéis & - Apenas Saturno apresenta. \\
\hline
\end{tabular}

Em termos práticos, a Astrofísica dialoga de maneira interdisciplinar com as dúvidas, expectativas, ansiedades e medos dos participantes. Por exemplo, a grande maioria das perguntas demonstrou preocupação com as questões mais fundamentais da existência humana - de onde viemos e para onde vamos - e se a espécie humana é a única a habitar o Universo. Muitos dos idosos não conheciam de que forma (metodologias 
científicas) a ciência, e a Astrofísica em particular, obtêm leis e teorias para entender e descrever os fenômenos à nossa volta.

Pudemos perceber nos encontros com sujeitos da terceira idade que a Astronomia e a Astrofísica, por seu caráter transversal e interdisciplinar, são ricas em possibilidades sensoriais, que podem ser trabalhadas de maneira complexa na velhice, onde complexo não significa difícil ou inacessível - complexo é posto no sentido de que a Astronomia na velhice não precisa ser superficial, fragmentada, rasa, e nem focada nos conteúdos pelos conteúdos apenas.

A Astronomia pode revelar para a velhice, através da Física, da Matemática, da Química, da Biologia, da Filosofia, da História e da observação do céu e do exercício livre da imaginação, um novo mundo, entre os vários mundos que se abrem nessa fase da vida, de maneira significativa, no contexto das ideias de Ausubel (Ausubel, 1980). Isto é, é possível fazer da divulgação científica um exercício em que os conceitos não são palavras soltas, mas que fazem sentido para os idosos, na medida em que interagem com conhecimentos e experiências pré-existentes. Isto refuta a premissa de que a sensação de sentir limita a experiência do corpo, e faz com que a velhice perca de vista a possibilidade de trilhar e propor novos caminhos (Monteiro, 2005). Esse é, justamente, o caráter revolucionário de explorar a Astronomia na velhice.

\section{Considerações finais}

De forma geral, concluímos que as atividades de divulgação científica para a velhice foram realizadas com sucesso; que elas não apenas conseguiram despertar a curiosidade científica do grupo, mas também contribuíram para fortalecer a autoestima deles. As atividades de divulgação científica aplicadas no Projeto UNITI, aqui descritas, foram recebidas e vivenciadas pelos participantes com permanente e inabalável entusiasmo, participação, pontualidade, intervenções positivas, em uma verdadeira expressão de quem pensa o que diz e diz o que pensa, em uma relação amistosa com os professores. Os professores, de outro lado, vivenciaram uma experiência próxima, não de palestrante, mas de uma conversa íntegra, plena entre indivíduos em interação, que engrandeceu a todos. Daí nossa tendência em afirmar que foi uma experiência de sucesso.

Para experiências futuras, no entanto, seria importante detectar, a partir de estudos focados, as necessidades e os temas de interesse do público alvo. É importante não apenas promover cursos de áreas de especialização e interesses dos próprios divulgadores de ciência e tecnologia, mas ouvir o interesse do público.

Os relatos dos participantes e da coordenação da UNITI demonstraram a alegria e satisfação das idosas e dos idosos em descobrir mais sobre os fascínios do Universo e ter a possibilidade de contrapor seus "velhos conhecimentos". Embora os participantes do curso UNITI não possam ser tomados como um grupo que vivencia (em função de seus rendimentos e profissões desenvolvidas ao longo de suas histórias de vida) a realidade dura de grande parte dos idosos do nosso País - estigmatizados, indesejáveis, moeda cara de centros "caça-níquel" e de obras de caridade - ou experimentem o amargo esquecimento de amigos, familiares e do próprio Estado em asilos, percebe-se dessa experiência que, de fato, os idosos, independentemente da condição social, têm as mesmas necessidades de qualquer outro grupo social (crianças, jovens e adultos "economicamente ativos"), no que concerne o acesso à cultura científica, ao lazer, à saúde, à segurança, ao respeito, ao conhecimento.

Por fim, tivemos indícios de que a Astrofísica, por seu caráter agregador em variadas disciplinas e rico em possibilidades sensoriais, pode ser trabalhada de maneira complexa na velhice, em que complexo não significa difícil ou inacessível; complexo no sentido de que a Astrofísica na velhice não precisa ser superficial, fragmentada, rasa, e nem focada nos conteúdos pelos conteúdos apenas; a Astrofísica pode revelar para a velhice um novo mundo, de maneira ressignificada, refutando a premissa de que a sensação de se sentir 
limitada à experiência do corpo faz com que a velhice perca de vista a possibilidade de trilhar e propor novos caminhos (Monteiro, 2005).

\section{Agradecimentos}

Agradecimento especial aos coordenadores e integrantes do Programa UNITI da UFRGS e aos colegas do Departamento de Astronomia que, sem hesitar, aceitaram participar do projeto.

\section{Contribuições de cada autor}

Os autores A.A.A. e N.T.M. escreveram o texto final; A.A.A. planejou o projeto e atuou como coordenador e orientador da bolsista. N.T.M. ajudou na interpretação dos resultados.

\section{Notas}

${ }^{1}$ http://basenacionalcomum.mec.gov.br/\#/site/inicio e http://basenacionalcomum.mec.gov.br/images/BNCC EI EF 110518 versaofinal site.pdf

${ }^{2}$ Por exemplo, programas de preparação e de pós aposentadoria http://desaposentado.com.br/

\section{Referências}

Ausubel, D. P, Novak, J. D., \& Hanesian, H. (1980). Psicologia Educacional. 2. ed. Rio de Janeiro: Interamericana.

Bauman, Z. (1998). O mal-estar da pós-modernidade. Rio de Janeiro: Jorge Zahar.

Bourdieu, P. (1983). Questões de Sociologia. Rio de Janeiro: Marco Zero.

Conselho Nacional de Educação (CNE), Brasil (2011). Parecer CNE/CEB no 5/2011, aprovado em 5 de maio de 2011 Diretrizes Curriculares Nacionais para o Ensino Médio.

Fórum dos Pró-Reitores de Extensão das Universidades Públicas Brasileiras - FORPROEX (2007). Extensão Universitária: Organização e sistematização. Universidade Federal de Minas Gerais, PROEX, COOPMED Editora.

Secretaria de Educação Fundamental (1998). Parâmetros curriculares nacionais: Ciências Naturais. Brasília: Secretaria de Educação Fundamental - MEC/ SEF.

Chaui, M. (1995). Cultura política e política cultural. Estudos Avançados. 9, 23.

Chevallard, Y, \& Johsua, M. A. (1982). Um exemplo de análise de transposição didática: A noção de distância. vol. 3.1, Grenobel: La Pensée Sauvage.

Debert, G. G. (2004). A reinvenção da velhice. São Paulo: EDUSP.

Freire, P. (1996). Pedagogia da autonomia: Saberes necessários à prática educativa. São Paulo: Paz e Terra.

Hoffmann, J. L. (2017). Um diálogo sobre as concepções alternativas presentes no ensino das Ciências. Arquivos do MUDI, 21(3), 90-101.

Krause, J. C., \& Scheid, N. M. J. (2018). Concepções alternativas sobre conceitos básicos de Física de estudantes ingressantes em curso superior da área tecnológica: Um estudo comparativo. Espaço Pedagógico, 25(2), 227-240.

Larrosa, J. (2018). Esperando não se sabe o que: Sobre o ofício de professor. 1. ed. Belo Horizonte: Autêntica Editora. 
Mannheim, K. (1993). El problema de las generaciones. Reis: Revista Española de Investigaciones Sociológicas 62, 193242.

Ministério da Educação, Brasil (S/d). Base Nacional Comum Curricular. Brasília: Ministério da Educação. Recuperado de: http://basenacionalcomum.mec.gov.br/images/BNCC EI EF 110518 versaofinal site.pdf

Monteiro, P. P. (2005). Envelhecer: Histórias, encontros, transformações. 3. edição. Belo Horizonte: Autêntica.

Moreira, I. de C., \& Massarani, L. A divulgação científica no Rio de Janeiro: Algumas reflexões sobre a década de 20. História, Ciências, Saúde - Manguinhos, 7(3), 627-651, 2001.

Organização Mundial de Saúde (OMS). Envelhecimento Ativo: Uma política de Saúde. Brasília: OMS, 2005. Recuperado de: https://bvsms.saude.gov.br/bvs/publicacoes/envelhecimento ativo.pdf

Patiño Barba, Ma. de L., Gonzalez, J. P., \& Massarani, L. (2017). Diagnóstico de la divulgación de la ciencia en América: Una mirada a la práctica de campo. León, Gto. México: Fibonacci-Innovación y Cultura Científica, A.C., RedPOP.

Peduzzi, S. S. (2005). Concepções alternativas em mecânica. In M. Pietrocola (Org.). Ensino de Física: Conteúdo, metodologia e epistemologia em uma concepção integradora. (pp. 53-75), Florianópolis: Editora da UFSC.

Silveira, M. L. (2013). Dificuldades de aprendizagem e concepções alternativas em Biologia: A visão de professores em formação sobre o conteúdo de citologia. (Dissertação de Mestrado Profissional em Ensino de Ciências Naturais e Matemática). Universidade Federal do Rio Grande do Norte, Natal, Brasil.

Valadares, E. C. (2001). Novas estratégias de divulgação científica e de revitalização do ensino de ciências nas escolas. Física na Escola, 2, (2), 10-13.

Como citar este artigo:

Alves-Brito, A., \& Massoni, N. T. (2020). O papel da divulgação científica em Astrofísica na velhice: Relato de uma experiência na extensão universitária. Revista Brasileira de Extensão Universitária, 11(2), $199-212$. https://periodicos.uffs.edu.br/index.php/RBEU/article/view/11423/pdf 